\title{
Intensive seismic activity around the Nankai trough revealed by DONET ocean-floor seismic observations
}

\author{
Masaru Nakano, Takeshi Nakamura, Shin’ichiro Kamiya, Michihiro Ohori*, and Yoshiyuki Kaneda \\ Earthquake and Tsunami Research Project for Disaster Prevention, \\ Japan Agency for Marine-Earth Science and Technology (JAMSTEC), Yokohama 236-0001, Japan \\ (Received February 20, 2012; Revised May 15, 2012; Accepted May 18, 2012; Online published February 19, 2013)
}

\begin{abstract}
Megathrust earthquakes anticipated in the Nankai trough will likely cause severe damage in central and western Japan. The Dense Oceanfloor Network System for Earthquakes and Tsunamis (DONET), a network of permanent ocean-bottom seismic stations for the early detection of earthquakes and tsunamis developed by the Japan Agency for Marine-Earth Science and Technology (JAMSTEC), is in place above the expected source region of such earthquakes. Data from DONET sensors are transmitted in real time to our laboratory at JAMSTEC. Intensive ongoing seismic activity is being detected off the Kii Peninsula by DONET, mainly distributed in three clusters that overlap with the aftershock distribution of the 2004 off the Kii Peninsula earthquakes $\left(M_{\text {JMA }}=7.1\right.$ and 7.4), and most of them are also aftershocks of the 2004 earthquakes. Some are linearly distributed on a different trend from the strike of the 2004 foreshock and mainshock fault planes. This result implies that the 2004 events triggered seismic activity on different faults on the subducting Philippine Sea plate. We also observed changes in seismic activity caused by the 2011 Tohoku-oki earthquake. These results could not have been obtained with on-land observations alone, which indicates the importance of DONET for monitoring seismic activity along the Nankai trough.
\end{abstract}

Key words: Ocean-bottom seismograph, seismicity, Kumano fore-arc basin.

\section{Introduction}

Along the Nankai trough, southwest of Japan, where the Philippine Sea plate is subducting beneath the overriding Eurasian plate, megathrust earthquakes have occurred repeatedly at intervals of 100-150 years (e.g., Ando, 1975), causing severe damage in western and central Japan. The 1944 Tonankai $\left(M_{\mathrm{w}}=8.1\right)$ and 1946 Nankai $\left(M_{\mathrm{w}}=8.4\right)$ megathrust earthquakes ruptured the eastern and western segments of the trough, respectively. This repeated megathrust earthquake activity implies that another great earthquake may occur in the near future that would cause serious widespread damage in central to western Japan.

To monitor seismic activity in this region, the Japan Agency for Marine-Earth Science and Technology (JAMSTEC) developed the Dense Oceanfloor Network System for Earthquakes and Tsunamis (DONET) above the Tonankai earthquake source region off the Kii Peninsula (Kaneda et al., 2009; Kawaguchi et al., 2010). DONET ocean-bottom seismic and water-pressure observation stations are connected with an optical fiber cable, and data from the sensors are transferred in real time to our laboratory at JAMSTEC. The seismic and water-pressure obser-

\footnotetext{
*Now at Research Institute of Nuclear Engineering, Fukui University, Japan.

Copyright (C) The Society of Geomagnetism and Earth, Planetary and Space Sciences (SGEPSS); The Seismological Society of Japan; The Volcanological Society of Japan; The Geodetic Society of Japan; The Japanese Society for Planetary Sciences; TERRAPUB
}

doi:10.5047/eps.2012.05.013 vations made by the DONET stations immediately above the source region of megathrust earthquakes improve our ability to detect earthquakes and tsunamis.

Seismic airgun surveys have been repeatedly carried out in this region to reveal the seismic velocity structures in the subduction zone (e.g., Mochizuki et al., 1998; Nakanishi et al., 2002, 2008; Park et al., 2002; Kodaira et al., 2006), and natural earthquake activity has been investigated by using observations made by pop-up-type ocean-bottom seismographs (OBSs) (Obana et al., 2004, 2005, 2009). On 5 September, 2004, a sequence of large earthquakes (off the Kii Peninsula earthquakes, $M_{\mathrm{JMA}}=7.1$ and 7.4) occurred in this region. The foreshock and mainshock are considered to have ruptured different fault planes, although the fault model is still controversial (e.g. Saito et al., 2010). The aftershock distribution was obtained from OBS observations (Sakai et al., 2005; Obana et al., 2009), and their centroid moment tensor (CMT) solutions were determined (Ito et $a l ., 2005)$. Very low-frequency (VLF) earthquakes (Obara and Ito, 2005; Ito and Obara, 2006a, b; Ito et al., 2009) and episodes of low-frequency tremor (Obana and Kodaira, 2009) are also known to have occurred in the shallow accretionary prism in this region. These anomalous events are considered to be caused by the dynamic deformation of the accretionary prism (Ito and Obara, 2006a).

Numerical studies have also been conducted to clarify the mechanisms of megathrust earthquakes along the Nankai trough. Hori et al. (2004) showed that it is important to incorporate the geometry of the subducting oceanic plate into the model space, because lateral variations in the frictional 
properties of the subducting plate can control the nucleation position of giant earthquakes. Kodaira et al. (2006) showed that weak fracture zones in the subducting oceanic plate are the key to the segmentation of megathrust earthquakes, because deformation in these zones releases accumulated stress. Mapping such structures from seismic observations is therefore important for constructing detailed structural models for the simulation of megathrust earthquakes.

In this study, we used data from DONET to determine hypocenters and to investigate the spatiotemporal distribution of seismic activity off the Kii Peninsula. We found much more active seismicity around the Nankai trough than had been detected by on-land seismic observations. We then examined the seismo-tectonic implications of the present seismic activity.

\section{DONET Ocean-Floor Observation Network}

DONET is deployed on the ocean floor in the Kumano fore-arc basin (Fig. 1). This newly-developed network is a cabled ocean-bottom observation system (Kaneda et al., 2009; Kawaguchi et al., 2010) consisting of 20 permanent stations deployed at intervals of 10 to $30 \mathrm{~km}$. Each station is equipped with a broadband seismometer (Guralp CMG-3T, flat velocity response from $100 \mathrm{~Hz}$ to $360 \mathrm{~s}$ ), a strong-motion seismometer (Metrozet TSA-100S, dynamic range of $\pm 4 \mathrm{G}$ and a bandwidth of DC to $225 \mathrm{~Hz}$ ), a hydrophone (High Tech. Inc. HTI-99-DY), a quartz pressure gauge (Paroscientific Inc.), a differential pressure gauge (Nichiyu Giken), and a thermometer (Nichiyu Giken). The seismometers are buried $1 \mathrm{~m}$ below the ocean floor to minimize noise from ocean-bottom currents, water temperature variations, and other environmental effects. Four stations are connected with an optical fiber cable to a science node, and the five science nodes are connected to a backbone cable. The backbone cable, which has a total length of $320 \mathrm{~km}$ and a looped geometry, sends the data to the landing station. Power is supplied from the landing station to the science nodes, which distribute the power to the stations and also relay signals between the stations and the landing station. The seismic and water-pressure signals obtained from the sensors are sampled at $200 \mathrm{~Hz}$ per channel by a 24-bit A/D converter on site and then transferred in real time to our laboratory via the landing station. The observed data are transmitted to the landing station in both clockwise and counterclockwise directions along the backbone cable loop, thus ensuring redundant data transmission. The multiple sensors enable each station to make wide-band seismic and pressure observations with a wide dynamic range. Each science node can be connected to as many as eight stations, so the observation network can be expanded in the future. Since the cables are detachable at the science node, in case of sensor failure, the problem sensor can be replaced by using a remotely-operated vehicle.

The construction of DONET began in 2010. Observations began when the first station was installed in March 2010. By January 2011, eight DONET stations were in operation. Three stations were added in March and six more in May 2011. By August 2011, with the installation of another three stations, all 20 planned stations were in operation.

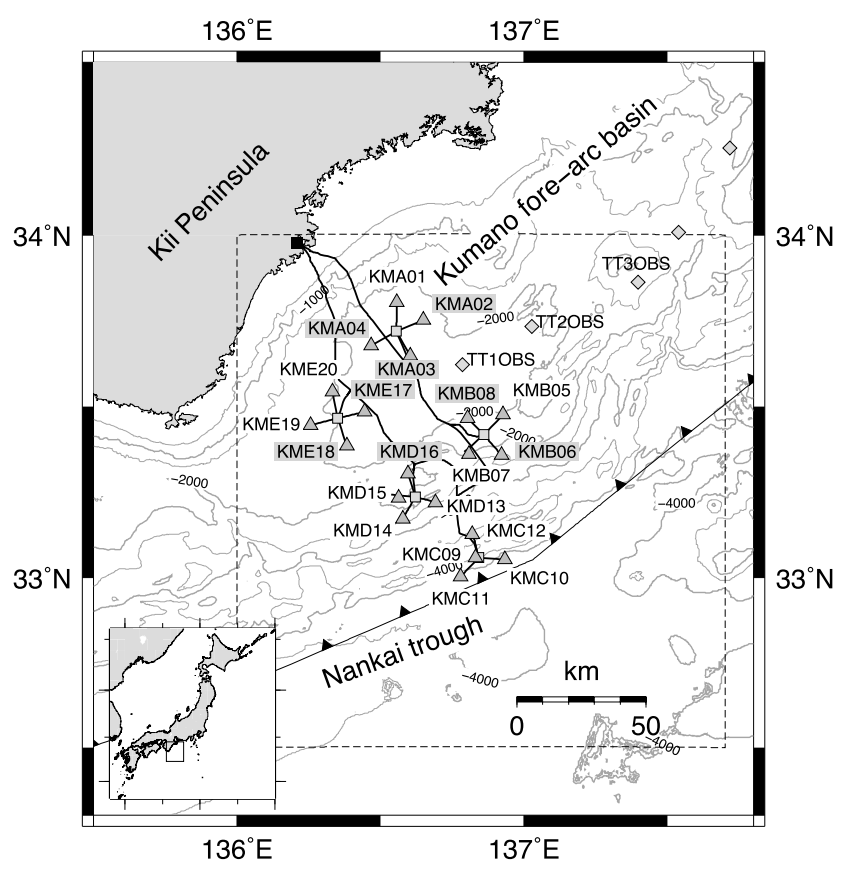

Fig. 1. Map showing the distribution of permanent ocean-bottom seismic stations off the Kii Peninsula. Dark gray triangles with station codes indicate the locations of DONET stations and light gray squares the locations of DONET science nodes; the black square is the landing station. The eight DONET stations installed by January 2011 are indicated by their codes on a gray background. Thick lines indicate the optical fiber cables connecting the DONET stations and the landing station. Light gray diamonds represent the locations of the permanent OBS stations deployed by JMA. Gray contours indicate the ocean-bottom topography. The line with triangular "teeth" indicates the estimated location of the Nankai trough axis. The rectangle enclosed by dashed lines is the area shown in Figs. 3, 5, 6, and 8. The inset shows the location of the plotted area in Japan.

\section{Development of the DONET Hypocenter Cata- logue}

\subsection{Method of hypocenter determination}

We determined the hypocenters of earthquakes observed by DONET after 8 January 2011, when eight DONET stations had been installed, by using three-component seismograms obtained from the broadband seismometers. We also used data obtained from permanent OBSs deployed by the Japan Meteorological Agency (JMA) off the Kii Peninsula (Fig. 1).

A two-pole Butterworth filter between 2 and $20 \mathrm{~Hz}$ was applied to the broadband seismic records before analysis to enhance the signals of local earthquakes. Figure 2 shows an example of the observed waveforms of an earthquake that occurred off the Kii Peninsula. Event triggering was based on an algorithm using the ratio of short-term to long-term averages of waveform amplitudes. We manually picked $P$ - and $S$-wave first motions for the triggered events. We assumed a layered velocity structure (Table 1) for the hypocenter determinations, which we based on the three-dimensional seismic structure for central and western Japan compiled by Nakamura et al. (2011), who determined the $P$-wave velocity $\left(V_{p}\right)$ structure in the study area by referring to the seismic surveys of Mochizuki et al. (1998), Nakanishi et al. (2002, 2008), and Kodaira et al. (2006). The $S$-wave velocity $\left(V_{s}\right)$ was calculated from the $V_{p} / V_{s}$ ra- 
Table 1. One-dimensional velocity structure used for the hypocenter determinations.

\begin{tabular}{ccc}
\hline Depth $(\mathrm{km})$ & Thickness $(\mathrm{km})$ & $P$ velocity $(\mathrm{km} / \mathrm{s})$ \\
\hline 0 & 2.64 & $1.50^{*}$ \\
2.64 & 0.86 & 2.00 \\
3.50 & 1.85 & 3.00 \\
5.35 & 2.97 & 4.00 \\
8.32 & 3.00 & 5.44 \\
11.32 & 3.00 & 6.50 \\
14.32 & - & 8.16 \\
\hline$*$ Water & &
\end{tabular}

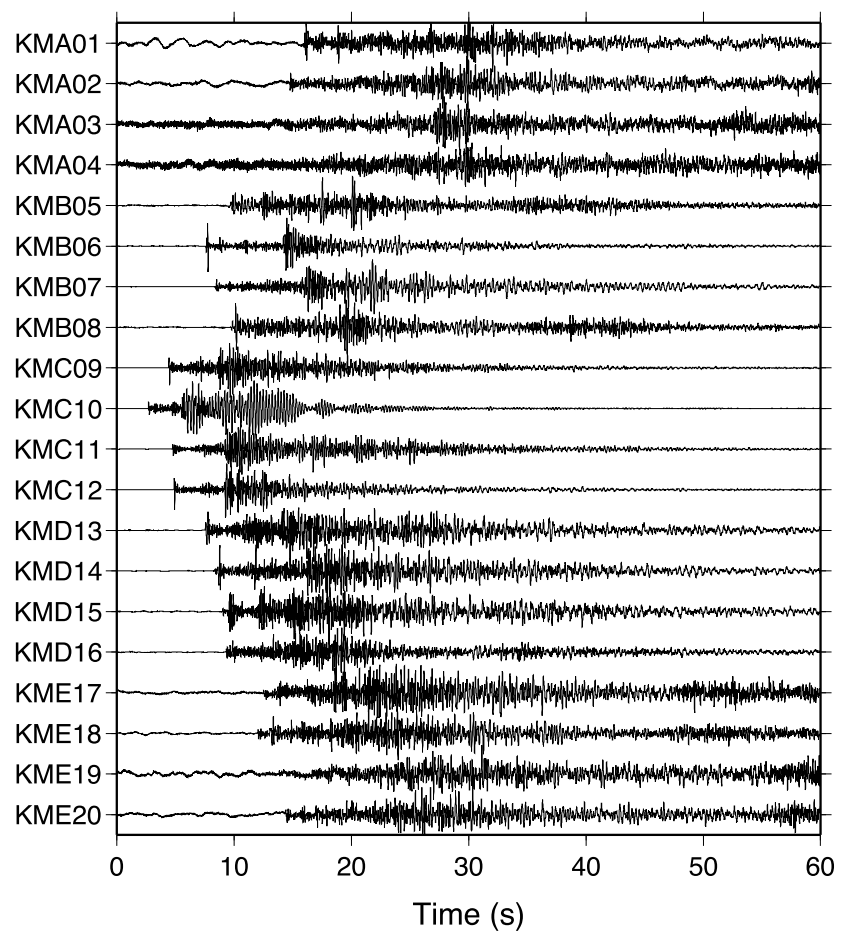

Fig. 2. Vertical velocity seismograms of an earthquake that occurred on 3 August, 2011, off the Kii Peninsula at a depth of $11 \mathrm{~km}\left(M_{\mathrm{L}}=3.2\right)$. Waveforms are band-pass filtered between 2 and $20 \mathrm{~Hz}$, and normalized by the maximum amplitude.

tio estimated from Wadachi diagrams (in which $S-P$ times are plotted against $P$-wave arrival times). In this region, the $V_{p} / V_{s}$ ratio averaged over the ray-path is 1.8 .

We used the method of Hirata and Matsu'ura (1987) for the hypocenter determinations. The local magnitude $\left(M_{\mathrm{L}}\right)$ was determined from the maximum amplitude of the vertical velocity seismogram (Watanabe, 1971). We did not use any data from on-land stations because the velocity structure of the shallower crust may differ significantly from that used in this study. We determined the hypocenters for earthquakes for which we had at least four $P$ and/or $S$ readings. We incorporated station corrections for $P$ - and $S$-wave arrival times, estimating the correction times for each station from the averaged differences between the observed and calculated travel times ( $O-C$ times). The root mean square (RMS) of the $O-C$ times was reduced from 0.275 to $0.204 \mathrm{~s}$ for the $P$-wave arrival time, and from 0.665 to $0.539 \mathrm{~s}$ for the $S$-wave arrival time, by incorporating the station corrections. The averaged estimation error of the hypocenter location was $1.4 \mathrm{~km}$ in the NS direction, $1.6 \mathrm{~km}$ in the $\mathrm{EW}$ direction, and $2.8 \mathrm{~km}$ in depth.

Figure 3 shows the resulting hypocenter distribution off the Kii Peninsula between 8 January and 31 August 2011. Seismic activity was intense around the trough axis. We note that the detection capability of the system and the precision of the source locations were enhanced by the installation of new stations during the analysis period. Most of the earthquakes in this region occurred at depths shallower than $50 \mathrm{~km}$. Examination of the frequency-magnitude distribution of the earthquakes (Fig. 4) showed that the $b$ value (defined as the negative of the slope on a log-linear frequency-magnitude plot) is almost constant at about 1 for earthquakes with magnitudes between 1 and 4, and it decreased to zero for earthquakes with magnitudes smaller than 0.8 , which is therefore the earthquake detection limit of DONET.

\subsection{Comparison with other hypocenter catalogues}

To evaluate the quality of the DONET hypocenter catalogue, we compared our result with the JMA hypocenter catalogue, which is based on both on-land observations and the JMA in-line OBSs. The JMA earthquake catalogue includes 185 events (Fig. 5), which is rather sparse compared with the DONET catalogue of 1377 events (Fig. 3). This result underscores the improved earthquake detection capability in this region made possible by DONET. Comparison of the source locations of earthquakes listed in both the JMA and DONET catalogues (Fig. 6) showed that in the area north of the trench axis, the JMA epicenters are systematically located northwest (closer to the Kii Peninsula) of the DONET epicenters, and in the area south of the trench axis, they are located southeast of the DONET epicenters, indicating that the JMA epicenter distribution is rather scattered around the trough axis. In addition, the JMA hypocenters are much deeper in this region than the DONET hypocenters. The average horizontal difference is $8.2 \mathrm{~km}$, and the average difference in depth is $24.7 \mathrm{~km}$. Previous studies also reported systematic differences in the source locations between the JMA catalogue and OBS-based hypocenters around the Nankai trough (Aoki et al., 2003; Sakai et al., 2005).

We next compared the earthquake magnitudes in the two catalogues (Fig. 7(a)) and the distribution of the differences between the two catalogues (Fig. 7(b)). The magnitudes of earthquakes in the DONET catalogue are on average larger by 0.38 than the JMA magnitudes. The differences in the source locations described above would affect the estimation of magnitude, but we cannot attribute the larger magnitudes of the DONET catalogue to the source location differences because the deeper source depths of the JMA catalogue would be expected to result in larger magnitude estimates. Since the DONET catalogue magnitudes were obtained from the maximum amplitudes of vertical seismograms, it is possible that the estimates were affected by amplification in the soft surface layer of the ocean bottom. Two of the earthquakes, in both the DONET and JMA catalogues, are also listed in the F-net CMT catalogue of the National Research Institute for Earthquake Prediction and Disaster Prevention (NIED) (Fukuyama et al., 1998; Kubo et al., 2002) (see Fig. 8 for their source locations). For 


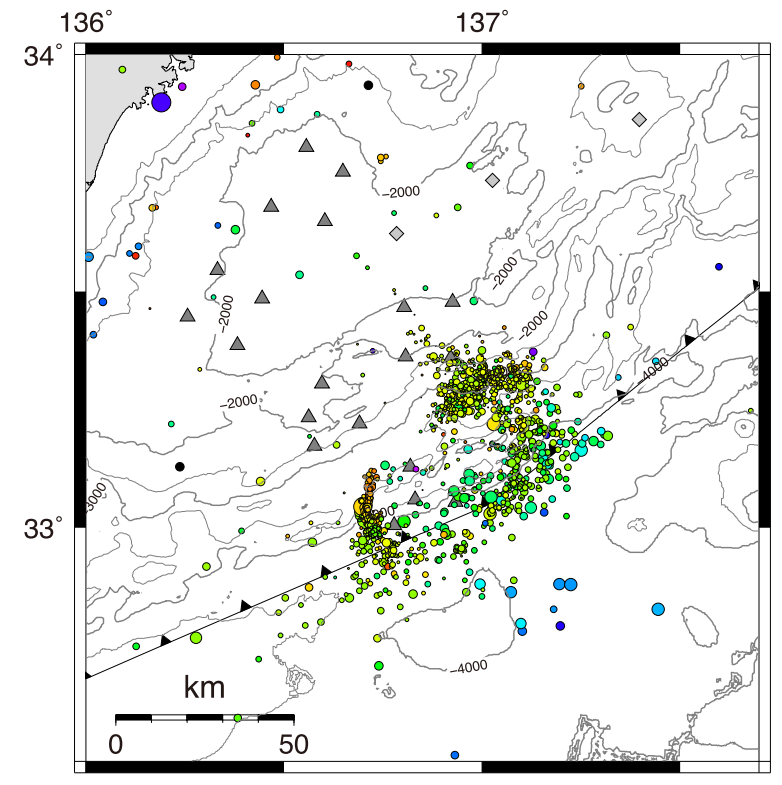

Depth $(\mathrm{km})$


Fig. 3. Hypocenter distribution off the Kii Peninsula obtained in this study. Circles indicate hypocenter locations. The color and size of the symbols represent source depth and earthquake magnitude, respectively. Gray triangles are DONET ocean-bottom seismic stations, and diamonds are JMA ocean-bottom seismic stations.

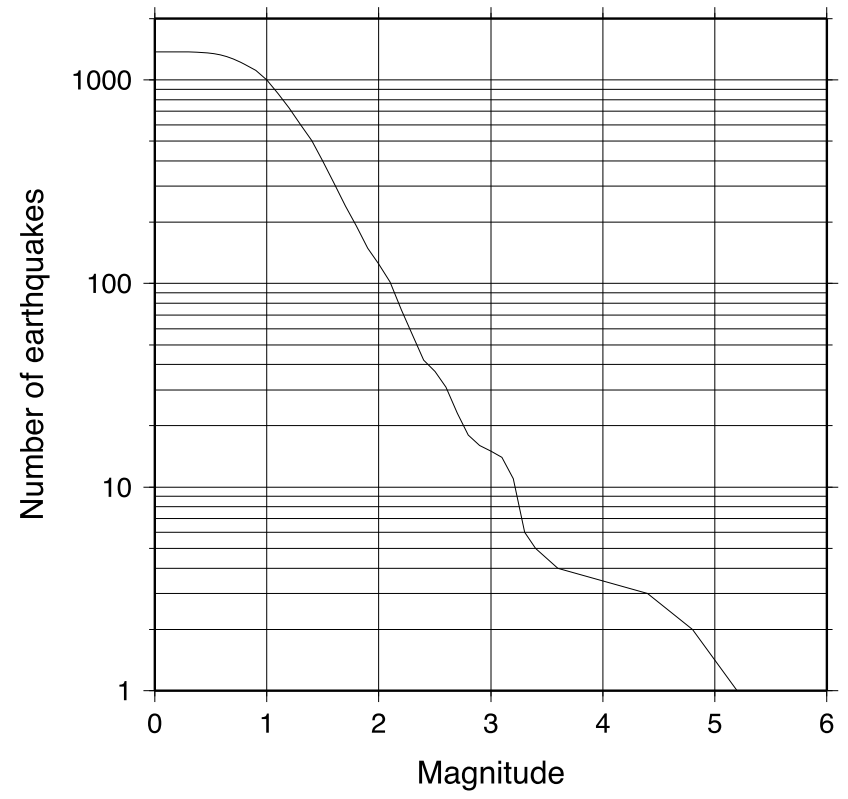

Fig. 4. Plot of earthquake frequency against magnitude for earthquakes off the Kii Peninsula detected in this study. The curve shows the cumulative number of earthquakes smaller than a given magnitude. the event that occurred on 18 January, 2011, the DONET and JMA local magnitudes were 4.4 and 3.8, respectively, and the F-net moment magnitude was 3.9. The other event, which occurred on 12 March, 2011, is also listed in the catalogue of Preliminary Determination of Earthquakes (PDE) of the U.S. Geological Survey (USGS). The PDE bodywave magnitude of this event is 4.8, the F-net moment magnitude is 4.7, and the DONET and JMA magnitudes are 4.8 and 4.3 , respectively. We thus need to analyze more events to clarify the cause of the magnitude difference.

\section{Hypocenter Relocation by the Double- Difference Method}

To examine the hypocenter distribution in more detail, we applied the double-difference (DD) method (Waldhauser and Ellsworth, 2000) to the DONET data. The DD method minimizes errors due to unmodeled velocity structures and improves the precision of relative source locations in an activity swarm. For the hypocenter relocation, we used the manually picked $P$ and $S$ arrival times, with $P$ and $S$ arrival time differences for 27,440 and 38,883 pairs, respectively. We then selected neighboring events, within $10 \mathrm{~km}$ of each other, and relocated the hypocenters. After the relocation, the RMS of the double-difference time residual was reduced from 276 to $63 \mathrm{~ms}$. We note that with the DD method the absolute location of earthquake clusters depends on the initial hypocenter distribution. We removed from the catalogue 
Depth $(\mathrm{km})$
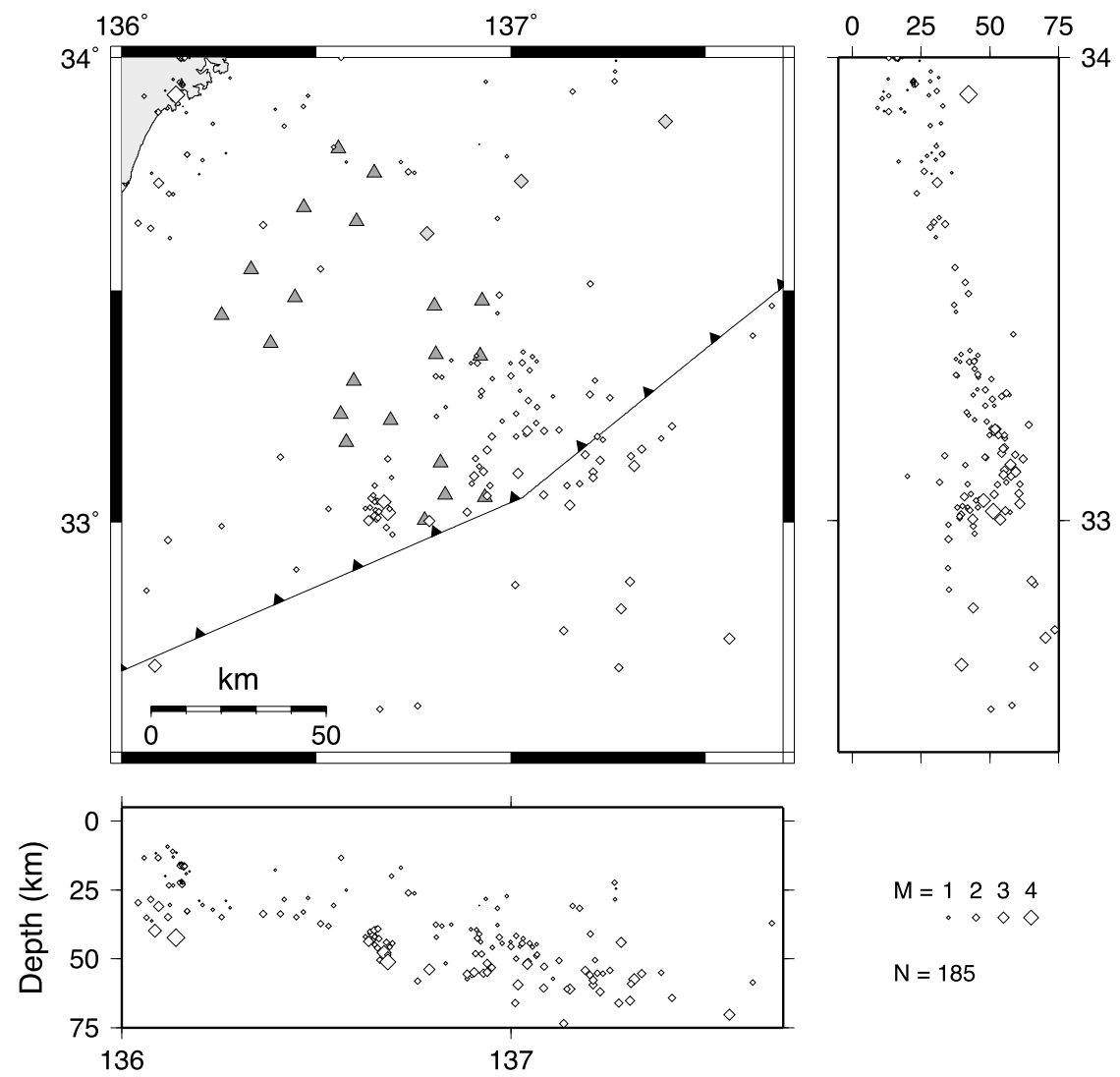

$M=123 \quad 34$

$\mathrm{N}=185$

Fig. 5. Hypocenter distribution of the JMA catalogue. Open diamonds indicate hypocenter locations. Other symbols are as in Fig. 3.
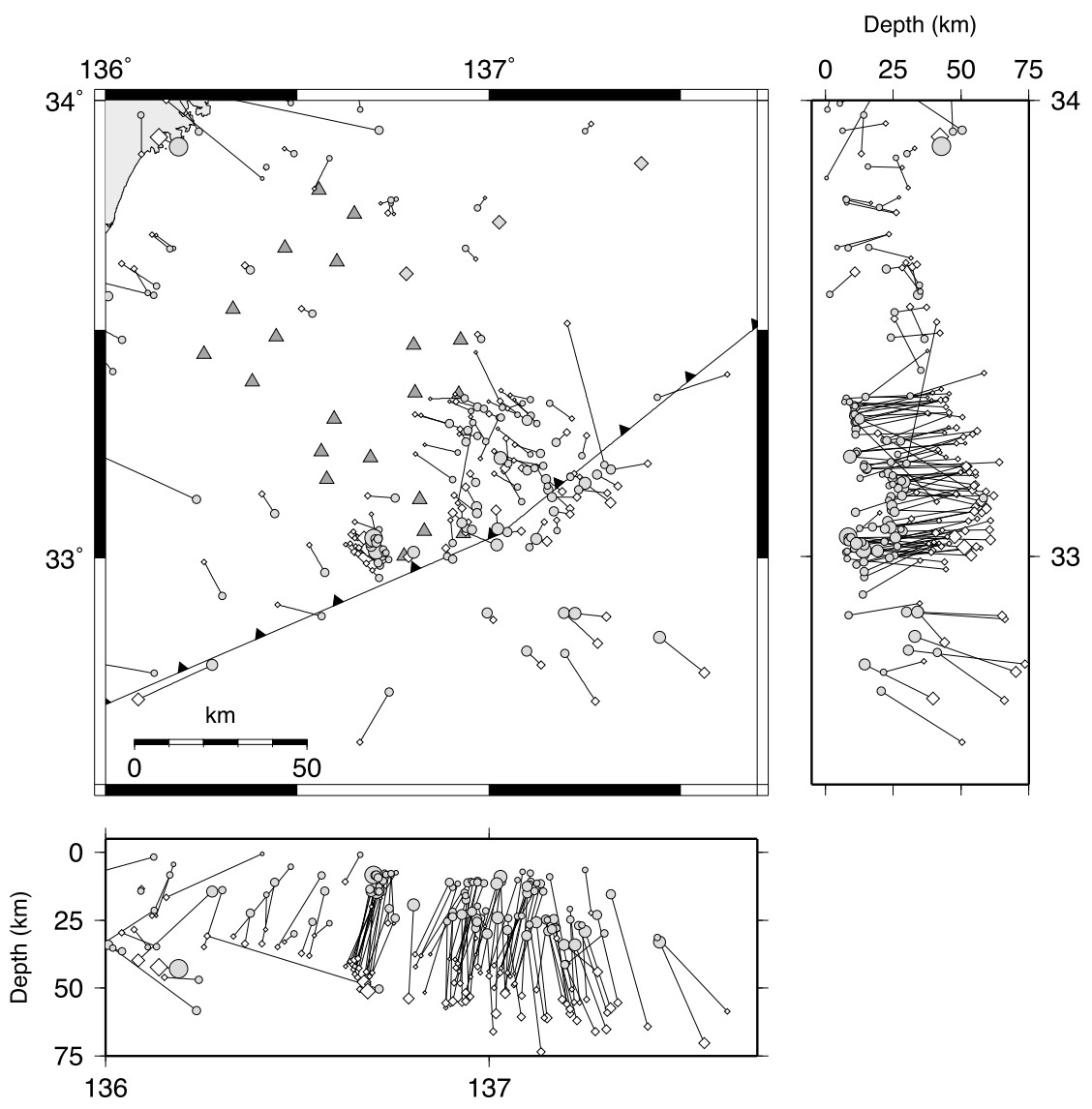

Fig. 6. Comparison of the hypocenter locations between the DONET (gray circles) and JMA (open diamonds) catalogues. Symbols for the same event in both catalogues are connected with a line. 

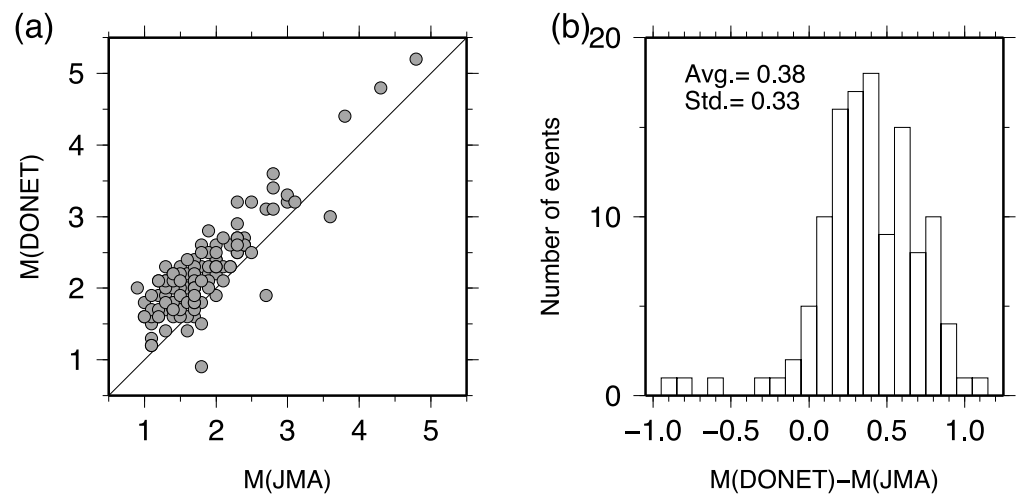

Fig. 7. (a) Correlation of earthquake magnitudes between the DONET and JMA catalogues. (b) Histogram of the magnitude differences between the DONET and JMA catalogues.



Fig. 8. Distribution of earthquakes relocated by the double-difference method (Waldhauser and Ellsworth, 2000). Earthquake clusters A, A', B, and $\mathrm{C}$ are circled. The NIED F-net CMT solutions for the largest earthquakes during the analysis period $\left(M_{\mathrm{L}}=4.4,18 \mathrm{January}, 2011 ; M_{\mathrm{L}}=4.8,12\right.$ March, 2011) and for the foreshock and mainshock of the 2004 events are also shown. Dashed lines show the locations of the KR9806 and NT0405 seismic surveys.

some scattered earthquakes that were not well grouped with other events in the obtained hypocenter distribution.

The seismic activity in this region occurs mainly in three clusters (Fig. 8). The earthquakes in cluster A, which is between station KMB06 and the trough axis, are distributed in a region extending EW about $50 \mathrm{~km}$ and NS about 30 $\mathrm{km}$. The source depth is between 10 and $30 \mathrm{~km}$. Cluster $\mathrm{B}$ is south of cluster A, just below the trough axis. This cluster extends NE-SW about $60 \mathrm{~km}$ and is about $30 \mathrm{~km}$ wide. The earthquake hypocenters are relatively deep, between 20 and $50 \mathrm{~km}$. The earthquake magnitudes are also relatively large compared with those of other clusters, possibly because small earthquakes in this cluster were not well detected owing to the large distance between the cluster and the stations. Southwest of cluster B is a linear cluster of seismic activity with an NS alignment (cluster C). The source depth is about $10 \mathrm{~km}$ in the northern part of the cluster and more than $20 \mathrm{~km}$ in the southern part. The two largest earthquakes that occurred in this region during the analysis period $\left(M_{\mathrm{L}}=4.4,18\right.$ January, 2011 , and $M_{\mathrm{L}}=4.8,12$ March, 2011) are in this cluster. Next, we describe the activity in each cluster in detail. 

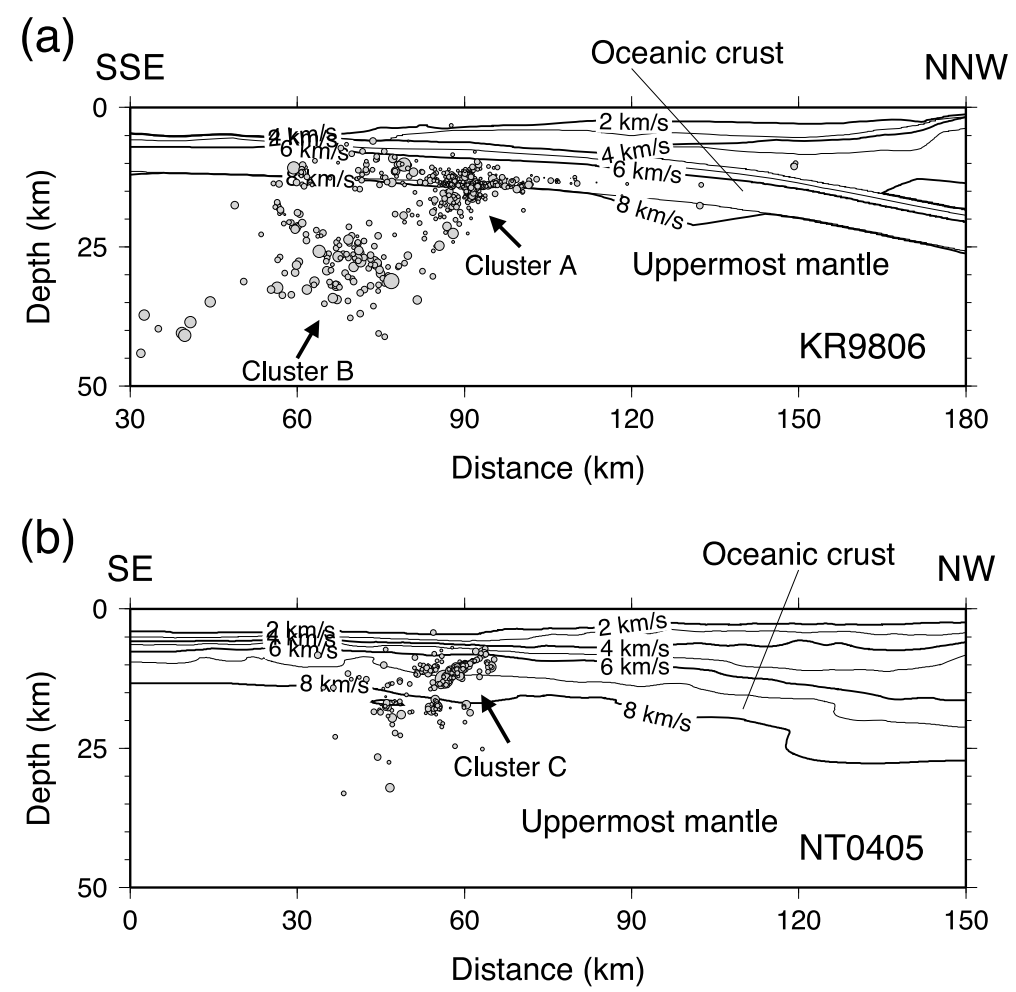

Fig. 9. Earthquake distributions superimposed on vertical sections of seismic structure along survey lines (a) KR9806 (Nakanishi et al., 2002 ) and (b) NT0405 (Nakanishi et al., 2008). Horizontal axis indicates distance along the survey line.

\section{Cluster A}

We compared the distribution of earthquakes in cluster A with the seismic structure along survey line KR9806 (location shown in Fig. 8) obtained by Nakanishi et al. (2002) (Fig. 9(a)). The earthquakes of this cluster occurred in the oceanic crust and uppermost mantle. Since this earthquake distribution well overlaps the aftershock distribution of the 2004 off the Kii Peninsula earthquakes (Sakai et al., 2005; Obana et al., 2009), we consider the present seismic activity to be aftershocks of the 2004 earthquakes. No seismic activity was evident in the accretionary prism, where the VLF earthquakes occurred (e.g., Obara and Ito, 2005; Ito and Obara, 2006a).

North of cluster A, we observed a distinct linear band, trending NNW-SSE, of a relatively low number of earthquakes (cluster $\mathrm{A}^{\prime}$ in Fig. 8). In this region, aftershocks were also relatively few (Sakai et al., 2005; Obana et al., 2009), but their CMT solutions, which were well determined by Ito et al. (2005), indicate vertical dip-slip or normal faults with the $T$-axis trending WNW-ESE. Both of these focal mechanisms have a nodal plane that strikes NNW-SSE, which corresponds to the direction of the earthquake alignment and implies that a fault with that orientation was the source of the earthquakes. These focal mechanisms are clearly different from the F-net CMT solutions of the 2004 foreshock and mainshock, which indicate a reverse fault with the $P$-axis trending NS. Therefore, these aftershocks occurred on a different fault from the 2004 foreshock and mainshock.

\section{Cluster B}

The cluster-B activity is rather deep, and the earthquake hypocenters are mostly in the uppermost mantle (Fig. 9(a)).
Before the 2004 earthquakes, seismic activity was observed in this region, but it was not as frequent (Obana et al., 2004). Since the epicenters of the 2004 foreshock and mainshock were in this region, the present activity is also considered to be aftershocks of the 2004 events. The hypocenter distribution of the present activity well overlaps the aftershock distribution (Sakai et al., 2005; Obana et al., 2009). The aftershock activity in this region extended westward to the region of cluster $\mathrm{C}$ immediately after the mainshock, but, at present, there is a gap between clusters B and C. The CMT solutions of the aftershocks are similar to those of the foreshock and mainshock (Ito et al., 2005). These earthquakes seem to be distributed on two planes, one in the southeastern region dipping to the north and one in the northwestern region dipping to the south, thus forming a "V" in crosssection (Fig. 9(a)). These planes are consistent with the fault planes of the CMT solutions of the 2004 foreshock and mainshock.

\section{Cluster C}

Cluster $\mathrm{C}$ is located at the western end of the aftershock activity of the 2004 earthquakes (Sakai et al., 2005). On the seismic section along survey line NT0405 (Nakanishi et al., 2008), the earthquakes can be seen to occur in the oceanic crust and uppermost mantle (Fig. 9(b)). The aftershock distribution of the 2004 earthquakes is also distinctly shallower than $10 \mathrm{~km}$ in this region (Sakai et al., 2005). Accordingly, we also consider the present activity in this cluster to be aftershocks of the 2004 events. The CMT solutions of the aftershocks in this region, obtained by Ito et al. (2005), display strike-slip faults with $P$ - and $T$-axes trending NNE-SSW and WNW-ESE, respectively. The Fnet focal mechanisms of the two $M_{\mathrm{L}}>4$ earthquakes in 
(a)

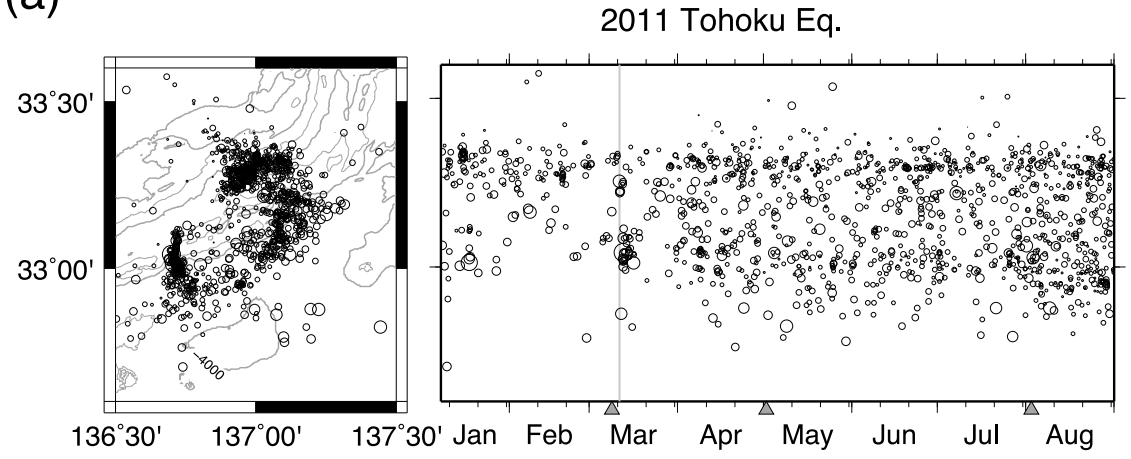

(b)



Fig. 10. (a) Spatiotemporal distribution of earthquakes around clusters A-C (see Fig. 8) obtained from the DONET hypocenter catalogue. Gray triangles indicate the timing when new stations are installed. (b) Spatiotemporal distribution obtained by using the $P$ and $S$ readings from only the eight stations that were installed before the 2011 Tohoku-oki earthquake. Left, map views; right, time series of earthquakes according to latitude. The vertical gray line in the right panels indicates the origin time of the 2011 Tohoku-oki earthquake.

this cluster similarly indicate strike-slip faults (Fig. 8). One of the nodal planes strikes NNW-SSE, corresponding to the earthquake alignment in the cluster. These focal mechanisms differ from those of the foreshock and mainshock of the 2004 event. Therefore, the seismic activity may be occurring on a fault different from the faults that caused the 2004 events, as in the case of cluster A'. Activity was also observed in this region before the 2004 events, although it was limited to a very narrow region (cluster D in figure 6 of Obana et al., 2005). The focal mechanisms of this early activity are very similar to those of the aftershocks, and the activity is attributed to deformation along pre-existing faults of the incoming Philippine Sea plate (Obana et al., 2005). West of cluster C, Obana et al. (2005) observed some earthquake clusters, but we could not find any distinct activity corresponding to these clusters in the present data.

\section{Discussion}

\subsection{Faults in the subducting Philippine Sea plate}

As explained in Section 4, we consider most of the present seismic activity off the Kii Peninsula to be aftershocks of the 2004 earthquakes. The F-net CMT solutions of the foreshock and mainshock in 2004 indicated reverse faults with the $P$-axis trending NS (see Fig. 8). This focal mechanism is obviously different from those of the aftershocks in clusters $\mathrm{A}^{\prime}$ and $\mathrm{C}$, suggesting the existence of strike-slip faults in the subducting Philippine Sea plate which differ from the faults responsible for the mainshock and aftershock of the 2004 event. Seismic activity on these faults would have been triggered by stress perturbations caused by the 2004 earthquakes. Saito et al. (2010) have suggested that a different fault model, a reverse fault with the $P$-axis trending NE-SW, for the mainshock better explains the dispersion of tsunami waves than the F-net CMT solution, but this fault model does not match the inferred faults of the cluster $\mathrm{A}^{\prime}$ and $\mathrm{C}$ aftershocks, either.

Pre-existing weak zones in a subducting oceanic plate play a key role in the segmentation of megathrust earthquakes. Kodaira et al. (2006) successfully simulated the segmentation and/or synchronization of giant earthquakes along the Nankai trough by incorporating a weak zone inferred from their findings of strike-slip faults in the oceanic plate. Without such a weak zone, Hori et al. (2004) could not reproduce the segmentation of the megathrust earthquakes, but found that they were always synchronized over the trough. Therefore, it is important to map such weak zones from seismic observations to understand the mechanism of giant earthquakes in a subduction zone.

\subsection{Temporal changes in seismic activity}

We examined the temporal changes in the seismic activity around clusters A-C (Fig. 10(a)) and found that the seismicity apparently increased after March 2011. This increase may correspond to the occurrence of the 11 March, 2011, Tohoku-oki earthquake. However, our ability to detect earthquakes also increased at this time because additional DONET stations were installed. To remove this artificial effect, we redetermined the earthquake hypocenters by restricting the $P$ and $S$ readings to those from only the eight stations that were already installed before the 2011 Tohoku-oki earthquake (stations indicated by their codes on 
(a)

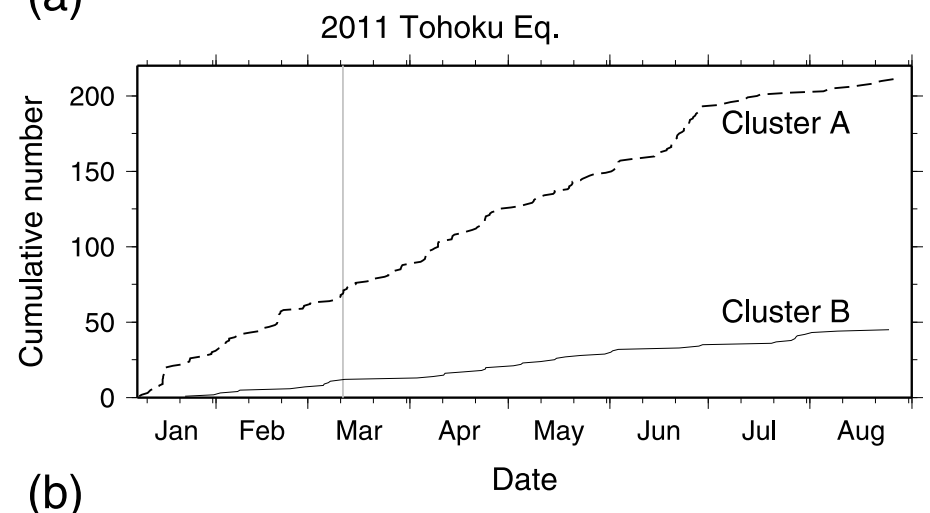

(b)

2011 Tohoku Eq.

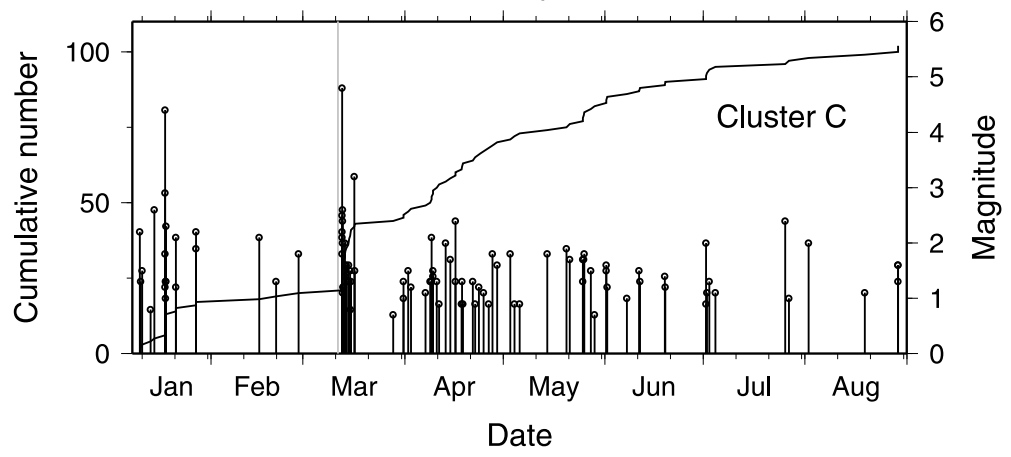

Fig. 11. (a) Cumulative number of earthquakes plotted against time for events of clusters A (dashed line) and B (solid line) (see Fig. 8). (b) Cumulative number of earthquakes (solid line) and earthquake magnitude (vertical bars) for cluster-C events.

a gray background in Fig. 1). We show in Fig. 10(b) those hypocenters determined by using at least six $P$ and/or $S$ readings. The seismicity is rather constant over the analysis period, although many earthquakes in cluster $\mathrm{C}$ are concentrated immediately after the 2011 Tohoku-oki earthquake.

We therefore plotted the cumulative number of earthquakes in each cluster as a function of time (Fig. 11) using the redetermined earthquake catalogue shown in Fig. 10(b). We recognized no distinct change in seismicity in clusters A or B in relation to the 2011 Tohoku-oki earthquake (Fig. 11(a)), but in cluster C, we observed a sudden increase in seismicity immediately after the Tohoku-oki earthquake (Fig. 11(b)). The cluster C activity was relatively low before the 2011 Tohoku-oki earthquake, but on 12 March, 2011, an earthquake of $M_{\mathrm{L}}=4.8$ was triggered, the largest event in the cluster during the analysis period. Subsequently, the seismicity in this cluster increased, and the increased seismicity continued until at least July 2011. Immediately after the 2011 Tohoku-oki earthquake, an increase in seismicity was observed mainly in eastern to central Japan (e.g., Hirose et al., 2011; Toda et al., 2011; Yukutake et al., 2011). In western Japan, seismicity was triggered on western Kyushu Island (Hirose et al., 2011), but no seismicity change has yet been reported along the Nankai trough.

We also found a change in the $b$-value of the earthquakes in cluster $\mathrm{C}$ after the 2011 Tohoku-oki earthquake (Fig. 12). The $b$-value of earthquakes smaller than magnitude 3 was about 0.5 before 11 March, 2011, and the value increased to about 1 afterwards. No change in the $b$-value was observed in the other clusters. Suyehiro et al. (1964) found that the $b$-value of foreshocks is smaller than that of aftershocks

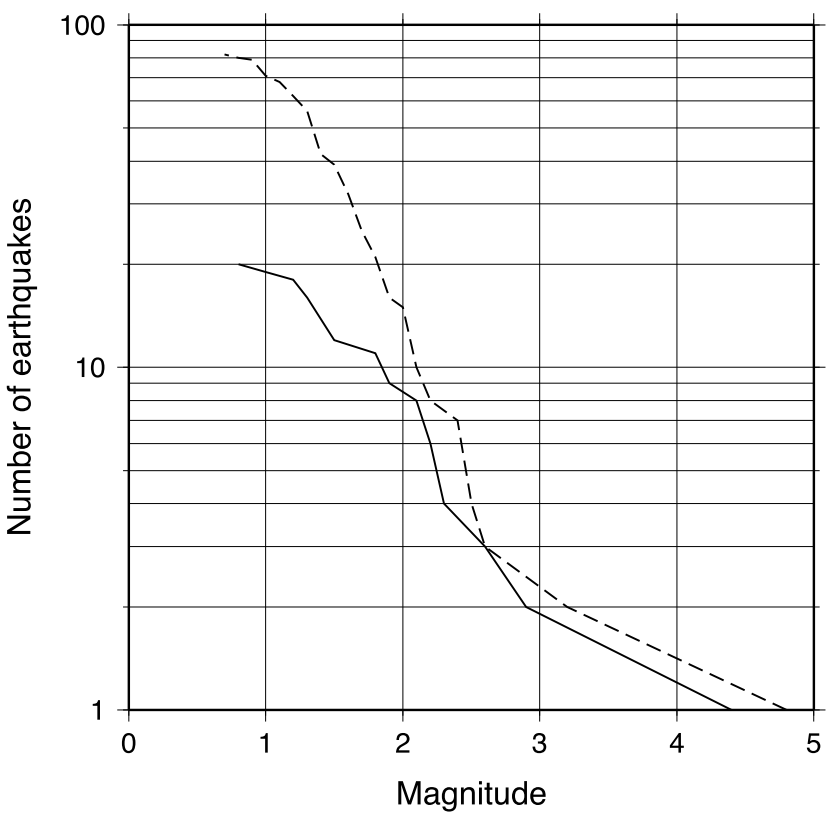

Fig. 12. Frequency-magnitude plots for cluster-C earthquakes (see Fig. 8). Solid and dashed lines indicate earthquakes before and after the 2011 Tohoku-oki earthquake, respectively.

even for a mainshock with a magnitude as small as 3.3. Wiemer and Wyss (1997) found that the $b$-value decreases as stress increases, and that a low $b$-value indicates a high level of stress in the source region. Therefore, we interpret the increase in the $b$-value to mean a decrease in the stress level caused mainly by the occurrence of the $M_{\mathrm{L}}=4.8$ 
earthquake, which was triggered by the 2011 Tohoku-oki earthquake. The anomalously low $b$-value of 0.5 before the event may indicate that the stress level was relatively high in the cluster $\mathrm{C}$ source region at that time.

\section{Conclusion}

The DONET ocean-bottom seismic observation network, deployed immediately above the source region of earthquakes along the Nankai trough, has much enhanced our ability to detect earthquakes off the Kii Peninsula compared with detection based on land observations alone. The hypocenter distribution obtained from the DONET observation data shows that most of the present seismic activity is from aftershocks of the 2004 off the Kii Peninsula earthquakes $\left(M_{\mathrm{JMA}}=7.1\right.$ and 7.4$)$. The seismic activity can be grouped into three main clusters. Detailed investigations of the source distributions indicate that there are several faults within the subducting Philippine Sea plate which are different from those that caused the foreshock and mainshock of the 2004 event. We also observed seismicity in this region triggered by the 2011 Tohoku-oki earthquake. These results indicate the value and importance of DONET for monitoring seismic activity along the Nankai trough.

Acknowledgments. We used the Japan Meteorological Agency Earthquake Catalogue in our analysis. We Thank F. Waldhauser for sharing the hypoDD program code. We thank K. Takizawa for the preparation of the seismic cross-section data KR9806 and NT0405. We greatly appreciate the comments of an anonymous reviewer. All the figures were drawn with Generic Mapping Tools (Wessel and Smith, 1998).

\section{References}

Ando, M., Source mechanisms and tectonic significance of historical earthquakes along the Nankai trough, Japan, Tectonophysics, 27, 119-140, 1975.

Aoki, G., Y. Yoshida, S. Harada, A. Yamazaki, Y. Ishikawa, M. Nakamura, M. Tanaka, S. Matsuda, K. Nakamura, M. Ogata, and M. Shirasaka, Seismicity along the Suruga-Nankai trough observed by pop-up type ocean bottom seismographs-In comparison with the JMA catalogue-, J. Seismol. Soc. Jpn. (Zisin), 55, 429-434, 2003 (in Japanese).

Fukuyama, E., M. Ishida, D. S. Dreger, and H. Kawai, Automated seismic moment tensor determination by using on-line broadband seismic waveforms, J. Seismol. Soc. Jpn. (Zisin), 51, 149-156, 1998 (in Japanese with English abstract).

Hirata, N. and M. Matsu'ura, Maximum-likelihood estimation of hypocenter with origin time eliminated using nonlinear inversion technique, Phys. Earth Planet. Inter., 47, 50-61, 1987.

Hirose, F., K. Miyaoka, N. Hayashimoto, T. Yamazaki, and M. Nakamura, Outline of the 2011 off the Pacific coast of Tohoku Earthquake $\left(M_{\mathrm{w}}\right.$ 9.0) - Seismicity: foreshocks, mainshock, aftershocks, and induced activity-, Earth Planets Space, 63, 513-518, doi:10.5047/eps.2011.05.019, 2011.

Hori, T., N. Kato, K. Hirahara, T. Baba, and Y. Kaneda, A numerical simulation of earthquake cycles along the Nankai Trough in southwest Japan: Lateral variation in frictional property due to the slab geometry controls the nucleation position, Earth Planet. Sci. Lett., 228, 215-226, 2004.

Ito, Y. and K. Obara, Dynamic deformation of the accretionary prism excites very low frequency earthquakes, Geophys. Res. Lett., 33, L02311, doi:10.1029/2005GL025270, 2006a.

Ito, Y. and K. Obara, Very low frequency earthquakes within accretionary prisms are very low stress-drop earthquakes, Geophys. Res. Lett., 33, L09302, doi:10.1029/2006GL025883, 2006b.

Ito, Y., T. Matsumoto, H. Kimura, H. Matsubayashi, K. Obara, and S. Sekiguchi, Spatial distribution of centroid moment tensor solutions for the 2004 off Kii peninsula earthquakes, Earth Planets Space, 57, 351$356,2005$.
Ito, Y., Y. Asano, and K. Obara, Very-low-frequency earthquakes indicate a transpressional stress regime in the Nankai accretionary prism, Geophys. Res. Lett., 36, L20309, doi:10.1029/2009GL039332, 2009.

Kaneda, Y., K. Kawaguchi, E. Araki, A. Sakuma, H. Matsumoto, T. Nakamura, S. Kamiya, K. Ariyoshi, T. Baba, M. Ohori, and T. Hori, Dense Ocean floor Network for Earthquakes and Tsunamis (DONET)Development and Data application for the mega thrust earthquakes around the Nankai trough-, Eos Trans. AGU, 90(52), Fall Meet. Suppl., Abstract S53A-1453, 2009.

Kawaguchi, K., E. Araki, S. Kaneko, T. Nishida, and T. Komine, Subsea engineering ROV and seafloor observatory construction, Proceedings of International Symposium on Underwater Technology 2010/International Workshop on Scientific Use of Submarine Cables and Related Technologies 2010, SSC11-1019, CD-ROM, 2010.

Kodaira, S., T. Hori, A. Ito, S. Miura, G. Fujie, J. O. Park, T. Baba, H. Sakaguchi, and Y. Kaneda, A cause of rupture segmentation and synchronization in the Nankai trough revealed by seismic imaging and numerical simulation, J. Geophys. Res., 111, B09301, doi:10.1029/2005JB004030, 2006

Kubo, A., E. Fukuyama, H. Kawai, and K. Nonomura, NIED seismic moment tensor catalogue for regional earthquakes around Japan: Auality test and application, Tectonophysics, 356, 23-48, 2002.

Mochizuki, K., G. Fujie, T. Sato, J. Kasahara, R. Hino, M. Shinohara, and K. Suyehiro, Heterogeneous crustal structure across a seismic block boundary along the Nankai Trough, Geophys. Res. Lett., 25, 2301-2304, 1998.

Nakamura, T., S. O. Citak, N. Takahashi, Y. Kaneda, M. Ohori, and T. Baba, A model of three-dimensional seismic structure in the source area of the Tokai-Tonankai-Nankai earthquake, Abstract of Japan Geoscience Union Meeting 2011, SSS035-P32, 2011.

Nakanishi, A., N. Takahashi, J. O. Park, S. Miura, S. Kodaira, Y. Kaneda, N. Hirata, T. Iwasaki, and M. Nakamura, Crustal structure across the coseismic rupture zone of the 1994 Tonankai earthquake, the central Nankai Trough seismogenic zone, J. Geophys. Res., 107, doi:10.1029/2001JB000424, 2002.

Nakanishi, A., S. Kodaira, S. Miura, A. Ito, T. Sato, J. O. Park, Y. Kido, and Y. Kaneda, Detailed structural image around splay-fault branching in the Nankai subduction seismogenic zone: Results from a highdensity ocean bottom seismic survey, J. Geophys. Res., 113, B03105, doi:10.1029/2007JB004974, 2008.

Obana, K. and S. Kodaira, Low-frequency tremors associated with reverse faults in a shallow accretionary prism, Earth Planet. Sci. Lett., 287, 168174, doi:10.1016/j.eps1.2009.08.005, 2009.

Obana, K., S. Kodaira, and Y. Kaneda, Microseismicity around rupture area of the 1944 Tonankai earthquake from ocean bottom seismograph observations, Earth Planet. Sci. Lett., 222, 561-572, doi:10.1016/j.epsl.2004.02.032, 2004.

Obana, K., S. Kodaira, and Y. Kaneda, Seismicity in the incoming/subducting Philippine Sea plate off the Kii Peninsula, central Nankai trough, J. Geophys. Res., 110, B11311, doi:10.1029/2004JB003487, 2005.

Obana, K., S. Kodaira, and Y. Kaneda, Seismicity at the eastern end of the 1944 Tonankai earthquake rupture area, Bull. Seismol. Soc. Am., 99, 110-122, doi:10.1785/0120070236, 2009.

Obara, K. and Y. Ito, Very low frequency earthquakes excited by the 2004 off the Kii peninsula earthquakes: A dynamic deformation process in the large accretionary prism, Earth Planets Space, 57, 321-326, 2005.

Park, J. O., T. Tsuru, S. Kodaira, P. R. Cummins, and Y. Kaneda, Splay fault branching along the Nankai subduction zone, Science, 297, 11571160, 2002.

Saito, T., K. Satake, and T. Furumura, Tsunami waveform inversion including dispersive waves: The 2004 earthquake off Kii Peninsula, Japan, $J$. Geophys. Res., 115, B06303, doi:10.1029/2009JB006884, 2010.

Sakai, S., T. Yamada, M. Shinohara, H. Hagiwara, T. Kanazawa, K. Obana, S. Kodaira, and Y. Kaneda, Urgent aftershock observation of the 2004 off the Kii Peninsula earthquake using ocean bottom seismometers, Earth Planets Space, 57, 363-368, 2005.

Suyehiro, S., T. Asada, and M. Ohtake, Foreshocks and aftershocks accompanying a perceptible earthquake in central Japan, Pap. Meteorol. Geophys., 15, 71-88, 1964.

Toda, S., J. Lin, and R. S. Stein, Using the $2011 M_{\mathrm{w}} 9.0$ off the Pacific coast of Tohoku Earthquake to test the Coulomb stress triggering hypothesis and to calculate faults brought closer to failure, Earth Planets Space, 63, 725-730, doi:10.5047/eps.2011.05.010, 2011.

Waldhauser, F. and W. L. Ellsworth, A double-difference earthquake location algorithm: Method and application to the northern Hayward fault, 
California, Bull. Seismol. Soc. Am., 90, 1352-1368, 2000.

Watanabe, H., Determination of earthquake magnitude at regional distance in and near Japan, J. Seismol. Soc. Jpn. (Zisin), 24, 189-200, 1971 (in Japanese with English abstract).

Wessel, P. and W. H. F. Smith, New version of the generic mapping tools released, Eos Trans. AGU, 76, 329, 1995.

Wiemer, S. and M. Wyss, Mapping the frequency-magnitude distribution in asperities: An improved technique to calculate recurrence times?, $J$. Geophys. Res., 102, 15,115-15,128, 1997.
Yukutake, Y., R. Honda, M. Harada, T. Aketagawa, H. Ito, and A. Yoshida, Remotely-triggered seismicity in the Hakone volcano following the 2011 off the Pacific coast of Tohoku Earthquake, Earth Planets Space, 63, 737-740, doi:10.5047/eps.2011.05.004, 2011.

M. Nakano (e-mail: mnakano@jamstec.go.jp), T. Nakamura, S. Kamiya, M. Ohori, and Y. Kaneda 